DOI: $10.46523 /$ jarssc. 05.01 .08

Multidisciplinary, Open Access
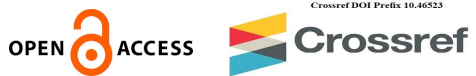

\title{
Happiness and Well-being among Adolescents in Rapidly Changing Social System
}

\author{
Anushradha \\ Visiting Faculty, MGM College of IT \& Management, Patna \\ E-mail: anushradha.kumar@gmail.com
}

\begin{abstract}
Happiness and well-being are basically related to each other and have different based upon the age group. In recent years, we've witnessed many changes in the social system like rise in the nuclear family system, both parents working or single parent raising kids, adoption of kids by LGBT community and the most recent one; the drastic change in lifestyle and daily routine of people, hindering their normal life due to Covid-19 pandemic. All these gradual and drastic changes are creating impact in the state of mind and well-being of people. Teenagers or adolescents are the most affected one due to change in their physical, physiological and emotional expressions, and it is a matter of great concern. Adolescence is the period following the onset of puberty during which a young person develops from a child into an adult. It describes the teenage years between 13 and 19 and can be considered the transitional stage from childhood to adulthood. Happiness as said is a state of mind and well-being is related to emotional, physical and mental health, and teenagers are very much vulnerable at this state. I have acknowledged the need of making teenagers aware of the happiness and fostering in them the aspects of well-being. My relevance of study is to find out what a teenager is experiencing at physical, emotional and mental level during the current scenario. Aim of my study is to understand the change in physical, psychological and emotional changes during the puberty and how it is affecting their emotional and mental well-being apart from happiness in the current scenario. My paper will study the observable changes among teenagers due their lifestyle, family and societal influence, and help teenagers in fostering healthy way of living and well-being. For the present study, a convenient random sampling of 50 adolescents was done. Data was gathered using questionnaire and later, a workshop was conducted for creating awareness. Secondary data included online blogs, newspapers and websites. Limitation of the research included limited sample size and small area of urban region.
\end{abstract}

Keywords: Adolescence, Healthy development, Changing social system, Happiness, Wellbeing 
Journal of Advance Research in Science and Social Science (JARSSC)

Official Publication of Indian Mental Health \& Research Centre

DOI: $10.46523 /$ jarssc. 05.01 .08

Multidisciplinary, Open Access
ISSN: $2582-2004$

Volume 05, Issue 01

open Access

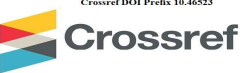

\section{Introduction}

Happiness is state of mind. And teenagers are usually happy when they are satisfied with their lives. The fact is nobody is happy all the time. Wellbeing comes from physical, mental and emotional health. It is also about understanding our emotions, taking part in different activities, having good relationships and social connections finding meaning in life and feeling that you are doing well.

Happiness and wellbeing are basically related to each other and have different connotations based upon the age group. In the recent years, we've witnessed many changes in the social system like rise in the nuclear family system, both parents working or single parent raising kids, adoption of kids by LGBTQ community and the recent one; the drastic change in lifestyle and daily routine of people, hindering their normal life due to Covid19 pandemic. All these gradual and drastic changes are creating impact in the state of mind and wellbeing of people. Teenagers or adolescents are the most affected one due to change in their physical, physiological and emotional expressions, which is a matter of great concern.

Adolescence is the period of following the onset of puberty during which a young person develops from a child into an adult. It describes the teenage years between $13 \& 19$ and can be considered as the transitional stage from childhood to adulthood. Happiness as said is a state of mind and wellbeing is related to emotional, physical and mental health; teenagers are very much vulnerable at this state.

I have acknowledged the need of making teenagers aware of the happiness and fostering in them the aspects of wellbeing. My relevance of study is finding out what a teenager is experiencing at physical, emotional and mental level during the current scenario.

As human being, society or Nation, we are committed to assist the youth or youngsters to become healthy and productive adults. My purpose is to provide an essential resource for people like community partners, schools and colleges or parents who lives with youth or adolescents for the maintenance of their happiness along with well-being. Other than infancy, teenage is the only period when human beings develop so much; and that too in such a short period. Adolescence is the period during which child develop (50\%) of their adult body, become capable of reproduction and also experience and make transformation in their thought 
Journal of Advance Research in Science and Social Science (JARSSC)

Official Publication of Indian Mental Health \& Research Centre

DOI: $10.46523 /$ jarssc. 05.01 .08

Multidisciplinary, Open Access
ISSN: $2582-2004$

Volume 05, Issue 01

process or we can say psychological wellbeing. All these changes occur in the context of rapidly changing social sphere.

I feel we must have a positive outlook and have a healthy perspective. It is considered as time and opportunity for growth development where teens succeed in school, only when they are well connected with their families and community, taking part in different activities in life and developing as healthy personnel. But, sometimes in community, opportunity turns into a turmoil leading to serious problem such as substance abuse, violence giving bad emotional experiences. But it is time of concentrated social, emotional and cognitive development and taking all aspects seriously.

In such transitional phase, positive attributes can be fostered by providing them proper learning and experience. Some researchers have stated that healthy development is best by fostering in them the core values of competence, confidence, connection, character, caring attitude, in them. It is only developed in adolescents by the kind of experiences they have in their own life. The young people become competent by trying and practising new things, builds confidence by taking responsibility. During earlier times, we can say before mid-80's it was found that the adolescent growth and development largely focused on the way teens act, and rarely on the surrounding or the environment where the child was growing up, whether it's at home, in front of TV, with friends in school or at work.

A community and environment apart from their family play an important role in their development. And it is essential to understand the strengths and needs of adolescents to reduce the risk of the environment for their well-being.

\section{Objective:}

The purpose of my research is to serve as an essential resource for healthy growth and development of teens along with the maintenance of their happiness and wellbeing. As we studied that the changing social system is giving a marked difference in the wellbeing of adolescents. This phase is very critical physically, cognitively and emotionally bringing great turmoil in their mood and emotions, and all these are dealt individually. Understanding this emotion can allow us to sustain appreciation and compassion for the joys and aggravations of adolescents: the ebullience, the insecurities, the risk taking, and the stunning growth in competence. 
Journal of Advance Research in Science and Social Science (JARSSC)

Official Publication of Indian Mental Health \& Research Centre

DOI: $10.46523 /$ jarssc. 05.01 .08

Multidisciplinary, Open Access
ISSN: $2582-2004$

Volume 05, Issue 01

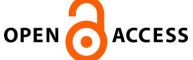

Crossref

Healthy adolescents' development describes the changes that happens during adolescence and how as an adult we can promote healthy development. The evidence of my research is based on the minor key idea, which include some valuable inputs: a normal healthy development is uneven; young people develop positive attributes through learning and experience; the larger community plays a fundamental and essential role in helping young people more successfully into adulthood.

Adolescence is a time of opportunity not turmoil - evidences shows that successful and healthy teens are attached to their families, and their community and emerge out of their teenage without facing problems like substance abuse or violence in movement. Due to intensified emotions, experience can be filled with angst and confusion. But they are a time of concentrated social, emotional and cognitive development.

Young people develop positive attributes through learning and experience - the researches have contributed and suggested that healthy development is best promoted by creating opportunities to develop core assets through their experiences in life. The positive youth development is framework expands the traditional focus on reducing risks.

\section{Aim of the Study}

1. To understand the change in physical, psychological and emotional changes during the puberty.

2. To study the factors affecting their emotional and mental well-being apart from happiness in the current scenario.

3. To find out the observable behavioural changes.

4. To study the role of changing social system, which include-

a. Rise in nuclear family system,

b. Both parents working,

c. Single parent raising the kid,

d. Adoption of kids by LGBTQ community, and

e. Drastic changes in lifestyle due to Covid-19 Pandemic.

\section{Review of Literature}

A study was conducted on development of subjective well-being in adolescence Ricarda Stienmayr, Linda Wirthwein, Laura Modler, Margaret M Barry investigated the intraindividual 
Journal of Advance Research in Science and Social Science (JARSSC)

Official Publication of Indian Mental Health \& Research Centre

DOI: $10.46523 /$ jarssc. 05.01 .08

Multidisciplinary, Open Access
ISSN: $2582-2004$

Volume 05, Issue 01

changes in subjective well-being and the factors associated with adolescents. Despite the importance of subjective well-being (SWB) for students' mental and physical health, there is a lack of longitudinal studies investigating the development of SWB in adolescents and what factors are associated with it over time. The present study seeks to shed further light on this question by investigating adolescents longitudinally. A sample of German academic tracks students $(N=476)$ from five schools were followed longitudinally over a time period of 30 months with four measurement points from Grade 11 to Grade 13. Alongside the longitudinal assessment of SWB (mood and life satisfaction), a range of other factors were also assessed at t1 including; demographic factors (sex, age, socio-economic status (HISEI)), intelligence, grades (report cards provided by the schools), personality (neuroticism, extraversion) and perceived parental expectations and support. Latent growth curve models were conducted to investigate the development of SWB and its correlates. On average, mood and life satisfaction improved at the end of mandatory schooling. Changes in mood were associated with socioeconomic background; the higher the HISEI the more positive the change. As social comparisons in school performance are almost inevitable, schools should intervene to buffer the influence of school grades on students' SWB.

Psychological well-being among adolescents in the current scenario studied by Pravitha. M.R., Dr. R. Sembiyan. The research primarily investigated psychological well-being and for the study of the sample, random sampling of 50 adolescents were done.Tool used for data collection was Ryff's psychological well-being scale. It is the combination of personal growth, environmental mastery, autonomy, positive relations with others. Result was analysed using SPSS. Results indicated that socio-demographic variables do not influence adolescent psychological well-being, Gender and age are negatively related with psychological wellbeing. Stay in hostel is positively related to well-being.

Happiness among adolescent students with family and non-family factors in Thailand studied by Rossarin Sootipong Gray (2011), explored the family and non-family factors contributing to happiness amongst students aged $15-18$ in Thailand. Based on regression analysis, study found out that family factors are more important than non-family factors in explaining the variations in adolescent happiness. Adolescents spending more time with family are connected and with highest level of love are the happiest. Those living with both parents were happiest than those living with single parent. 
DOI: $10.46523 /$ jarssc. 05.01 .08

Multidisciplinary, Open Access

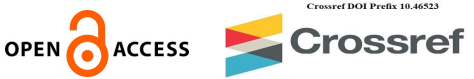

\section{Theoretical Framework and Hypothesis of Study}

The purpose of present study is to foster positive outlook and have a healthy perspective in growth and development of teens. But some opportunities turn into turmoil leading to serious development, such as violence, substance abuse, giving bad emotional experience. These include physical, cognitive and emotional development.

\section{Theoretical Framework of Physical, Cognitive \& Emotional Development among} Adolescents

Physical Development - Physical changes are the most noticeable signs of becoming adolescent. It is the puberty which affects the lives of teens in every aspect. Bodily changes lead to change in circle of peers, adult's view of teens and teens view of themselves. For girls, puberty starts at the age of 8 and rapidly at 10. The growth spur lasts for few years. In boys, the growth spur starts two year later than the girls, which means continue till the age of 17 or 18 in girls and till 21 in boys.

Puberty is triggered by the action of hormones in various parts of the body. Body image can be shaped by emotions, perceptions, physical sensation, experience, and moods. It can be powerfully influenced by cultural messages and societal standards.

How teens perceive their physical development -

1. It is about how they feel and move and looks in the mirror.

2. Body image can be shaped by emotions, perceptions, physical sensation, experience and mood.

3. Some teens mature early and some late, and it creates uncertainty in them of not looking different from their peers and friends.

4. Girls experience physical changes earlier than boys and challenges due to body changes.

5. The adolescent feels about their body also affects the way they feel about themselves as a whole.

The way they feel about their body can affect the way they feel about themselves as a whole.

\section{Cognitive Development}

New thinking skills develop with higher level of brain power to think in abstract terms, power to debate and question, about different challenges, future, set goals and solve problems. The three main components of adolescent cognitive skills are strengthening of their thinking skills 
Journal of Advance Research in Science and Social Science (JARSSC)

Official Publication of Indian Mental Health \& Research Centre

DOI: $10.46523 /$ jarssc. 05.01 .08

Multidisciplinary, Open Access
ISSN: $2582-2004$

Volume 05, Issue 01

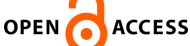

Crossref

in advance way, including multiple options and possibilities with a logical thought process. Secondly, development of abstract thinking skills of the things which cannot be seen, heard or touched. It allows one to think about faith, trust, love, belief and spirituality. Third, is the capability to think about thinking, process known as "meta-cognition". Meta-cognition allows young people to consider how they feel and what they are thinking and also involves being able to think about how one is perceived by others. It is useful in memorizing and thinking.

Recent neurological finding maps the brain development continues up to at least the age of 21 . Brain development even affects the way teens sleep and give rest to their brain. Adolescents sleep pattern differ from child and adults. Teenagers actually need 9-10 hours of sleep.

Risk taking in adolescents results in unhealthy consequences of alcohol and often drugs and tobacco on the developing teen brains. Cognitive impairment and brain damage can be seen due to alcohol poisoning. Nicotine or tobacco leads a depression or cardiac irregularities. Drugs damage the neuron leading to damaging the areas of impulse control and ability to experience the reward.

\section{Emotional Development}

Emotional competence is the ability to perceive, assess, and manage one's own emotions. Social competence is the capacity to be sensitive and effective in relating to other people. Emotional and social development incudes four areas Self-awareness which creates a feeling of what do I feel. Conscious attention needs to be paid to the feelings of teen to make it recognizable. Self-awareness is very important for undefined feelings which can lead to withdrawal or depressed feelings in adolescents. Social awareness which creates a feeling of what do other people feel. Having the understanding of the thoughts and feelings of others and appreciating the value of human differences are the consequences of social awareness. Selfmanagement which creates a feeling of how can I control my emotions.

Reason for increased emotions among teens.

- Hormones, bring physical changes in puberty, also affects mood and different responses in teens.

- Concern about their physical changes - height, weight, facial hair, development of breasts in girls are cause of sensitivity and heightened emotion in teens.

- Irregular meal pattern, skipping breakfast, fasting to lose weight can affect emotions. 
Journal of Advance Research in Science and Social Science (JARSSC)

Official Publication of Indian Mental Health \& Research Centre

DOI: $10.46523 /$ jarssc. 05.01 .08

Multidisciplinary, Open Access
ISSN: $2582-2004$

Volume 05, Issue 01

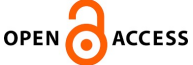

- Little sleep can lead to moodiness, gloominess, irritability and tendency to overreact.

- Relationship with peers, romantic equation, or social relationships with ups and downs experienced by teens lead to mood-to-mood swings.

Adolescents learn logical thinking, decision making, and problem-solving skills from their parents, caregiver and family.

\section{Hypothesis of Study}

1. Physical, emotional and cognitive development of adolescent have an influence on happiness and wellbeing.

2. Changing social system, such as rise in nuclear family system, both parents working, single parent raising the kid, adoption of kids by LGBTQ community, drastic changes in lifestyle due to Covid-19 Pandemic is putting negative impact on happiness and wellbeing.

3. Positive outlook and have a healthy perspective in growth and development of teens have good impact on happiness and wellbeing.

4. Situational crisis or turmoil leads to observable behavioural changes in teens.

5. Time and opportunity are created in schools, home and community for healthy growth and development of teens.

\section{Research Methodology}

The purpose of present study is to know the observable changes among teenagers due their lifestyle, family and societal influence, and help teenagers in fostering healthy way of living and well-being. The study will be descriptive in nature and will include exploratory research on the concern areas of physical, cognitive and emotional development affecting the happiness and wellbeing of the adolescents. I have tried to use latest concepts in management to highlight the situation in context of such problem. Both primary and secondary data has been used.

For the present study, a convenient random sampling method was used for the study with the sample size of 50 adolescents who were located in a small area of Urban region of Patna. Questionnaire was prepared and distributed for the test purpose and after that it was further modified and finally prepared to be administered among the sample respondents. 
Journal of Advance Research in Science and Social Science (JARSSC)

Official Publication of Indian Mental Health \& Research Centre

DOI: $10.46523 /$ jarssc. 05.01 .08

Multidisciplinary, Open Access
ISSN: $2582-2004$

Volume 05, Issue 01

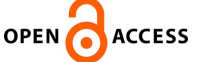

Data gathering was done using questionnaire in the area of happiness and wellbeing regarding, family relation, parenting, about their diet and sleep, physical activity or sleep, relationship with friends and peers, bullied or teased, sexual orientation, awareness about their happiness and wellbeing. Open ended questions were asked and later, a workshop was conducted for creating awareness and fostering in them positive outlook and have a healthy perspective in their growth and development. We had to rely both on primary and secondary data which included online blogs, newspapers.

\section{Observations and Findings}

1. Issues during Physical Development -

Worry about their appearance.

Excessive diet.

Exercise.

Being bullied, teased or excluded.

Affecting happiness and well-being - By creating depression, eating disorder giving several distorted views to their body like anorexia nervosa, bulimia nervosa, body dysmorphic disorder, muscle dysmorphia, using steroids.

2. Issues during Cognitive Development -

Increasing screen time

Living in lockdown

Pandemic situations like family crisis, isolation, etc.

Change in family system.

Less sleep. Effects of tobacco and drugs.

Affecting happiness and wellbeing - By damaging impulse control, irritant behaviour, lack of concentration, inability to de task.

3. Issues during Emotional Development -

Hormones - moods and emotions.

Concern about physical changes. 
Journal of Advance Research in Science and Social Science (JARSSC)

Official Publication of Indian Mental Health \& Research Centre

DOI: $10.46523 /$ jarssc. 05.01 .08

Multidisciplinary, Open Access
ISSN: $2582-2004$

Volume 05, Issue 01

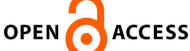

Crossref

Irregular routine.

Inadequate sleep.

Ups and down of social relationships.

Affecting happiness and wellbeing - By creating loneliness and depression, irritability, tendency to overreact.

\section{Discussion, Suggestions and Limitations}

A positive outlook and having a healthy perspective give teens time and opportunity for growth and development in this transition phase. Positive attributes can be provided to teens by giving them proper learning and experience. Some of the tips to boost teenage happiness and wellbeing are as follows -

We as parents, guardians, caregivers and society or community can boost a child's happiness by praises and encouragement, clear rules and boundaries, healthy family lifestyle and warm family relationships. These aspects are mentioned in details below -

- Praise, encouragement and positive attention - praise should be given to child when he behaves the way we want to encourage in them.

- Giving the child our attention, by giving hug or attending their outdoor activity or sports.

- Encourage your child to try out new things.

- Praising the child for who they are and also value their strengths. For example, you are really good at doing your task on time.

- Expressing your child that you of them when they are doing something tough. Like you really worked hard for your game and you did it.

- Rules and boundaries to be properly drawn - clear and fair rules make the life of the teenagers safe and smooth when so many changes are happening. If rules are made with mutual consent, it helps the child to stick to it smoothly and gives them a sense of maturity.

- Healthy Lifestyle - encourage good sleep habits, as sleeping for 8 to 10 hours is necessary for overall development of teens. Inculcate in them the habit of physical exercise in their daily routine. Encourage the child to make healthy food choice for 
Journal of Advance Research in Science and Social Science (JARSSC)

Official Publication of Indian Mental Health \& Research Centre

DOI: $10.46523 /$ jarssc. 05.01 .08

Multidisciplinary, Open Access
ISSN: $2582-2004$

Volume 05, Issue 01

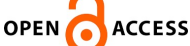

Crossref

proper growth and development. A child must help with the healthy balance between study, work and play. This will include planning daily routine and monitoring it silently.

- Family relationships - share and make memories together. For example, taking pictures on special occasion or event I $\mathrm{n}$ family or school and watching and remembering it later.

- Establish and maintain family rituals, like cook together, watch movies, or go for shakes or ice-creams after school sometimes.

- Older teenager gets happiness by getting freedom, but still need us and to be monitored time to time. It's about being respected, developing independently of parents, making their own friendship and social life and being taken seriously as individuals.

Wellbeing can be fostered in teenagers by taking care some of the important areas mentioned below -

- Physical Health - When the child takes care of themselves, wellbeing is naturally in a better state. They follow a routine and healthy life, taking proper sleep, doing physical exercise and physical activity, taking break from technology and this in turn maintain their physical fitness.

- Mental and emotional health - sound mental and emotional health is very important for well-being of a teenager and it can be fostered by providing support and care by parents and caregivers to them. It puts positive influence in child and helps them to develop; resilience, self-compassion and confidence.

- Positive focus - by appreciating good and positive feeling in life helps the child to become positive rather than overwhelming and keeping view of difficult times in perspective. It can be done on daily basis for few minutes by focusing on what they are grateful for.

- Relationships and social connections - a child needs closed and supportive family and friends, because relationship and social connections are vital for happiness and wellbeing of teenager.

- Develop meaning in life - meaning in life can be developed by doing good to others or by helping others. It can be developed by helping family and friends. And also, 
Journal of Advance Research in Science and Social Science (JARSSC)

Official Publication of Indian Mental Health \& Research Centre

DOI: $10.46523 /$ jarssc. 05.01 .08

Multidisciplinary, Open Access
ISSN: $2582-2004$

Volume 05, Issue 01

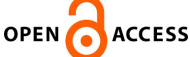

by slowly getting involved in community activity, like giving somebody their seat in the bus. It lights up the reward system in the brain which makes the child's feel good. This way they are less stressed.

- Goals and achievement - if the child have goal fitting their values, can be fun and attainable. We can help the child to use their strengths and it give the child a sense of purpose and achievement.

Apart from the suggestions given for boosting happiness and wellbeing in the above paras, the limitation of the research cannot be escaped and it included limited sample size, small area of Urban region, open ended question relating to day to activities.

\section{Conclusion}

We must appreciate the way what it is to be an adolescent. At no other age in life than teenage, human beings develop so rapidly and in so many different ways. Healthy development happens and the key areas supported by research shows firstly the most fundamental aspects of rapid changes in adolescence, which is normal. Second key idea is that regular and healthy idea is uneven. Thirdly, positive attributes are developed in adolescents through learning and development. Lastly, ideas say healthy development in the environment where teens spend time. We hope that through better understanding of adolescent development, we can be confident in fostering happiness and wellbeing in them. We must create an opportunity to develop core assets of competence by providing training and practice in specific skills; confidence by providing opportunities to experience success when trying something new; connection by building strong relationship with parents, caregivers, teachers or peers; character by providing opportunity of practicing increased self-control; being caring by taking care of young people. I can conclude by saying that researchers have found out that growing mindset and positive attitude helps in building well-being skills more easily. And its important to build realistic plan and stick to that plan. Lastly, happiness and wellbeing are related, but they are not the same thing. Teenagers can be happy because of some of the things that make up wellbeing, but they don't need all the things to be happy.

\section{Acknowledgement}

My research report is an opportunity to spend time with adolescents, parents and care givers through discussions, workshops and interactions which went a long way till completion, and I 
Journal of Advance Research in Science and Social Science (JARSSC)

Official Publication of Indian Mental Health \& Research Centre

DOI: $10.46523 /$ jarssc. 05.01 .08

Multidisciplinary, Open Access
ISSN: $2582-2004$

Volume 05, Issue 01

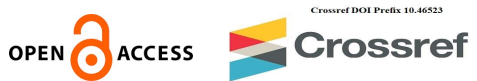

express my gratitude to them. This noble research touched upon myriad information, through interaction, references from various books, website, etc.

\section{References}

American Psychological Association. (2002). Developing adolescents: A reference for professionals. Washington DC: American Psychological Association.

Adolescent Health Working Group (2005). Body basics. Retrieved July 19, 2008, from http:/www.ahwg.net/resource/toolkit.htm

Steinberg, L., \& Morris, A.S. (2001). Adolescent development. Annual Review of Psychology, 52,83-110

Walsh, J. (2004). Why do they act? New York, NY: Free Press, 14-25.

Adolescent Health Working Group (2008). Behavioural Health. Retrieved July 19, 2009, from http://www.ahwg.net/resource/toolkit.htm.

Allen, J.P .Porter, M.R., \& McFrankland, F.C (2005). The two faces of adolescents' success with peers: adolescent popularity, social adaptation, and deviant behaviour. Child Development, 76(3), 742-760.

Article on teenage happiness and wellbeing.

Weiner, B. (1985). An attributional theory of achievement motivation and emotion. Psychological Review, 92, 548-573.

Weiner, B. (1986). An attribution theory of motivation and emotion. New York, NY 